\title{
Activation of ERK/MAP Kinase in the Amygdala Is Required for Memory Consolidation of Pavlovian Fear Conditioning
}

\author{
Glenn E. Schafe, ${ }^{1}$ Coleen M. Atkins, ${ }^{2}$ Michael W. Swank, ${ }^{3}$ Elizabeth P. Bauer, ${ }^{1}$ J. David Sweatt, ${ }^{2}$ and \\ Joseph E. LeDoux ${ }^{1}$
}

${ }^{1}$ W. M. Keck Foundation Laboratory of Neurobiology, Center for Neural Science, New York University, New York, New York 10003, 2Division of Neuroscience, Baylor College of Medicine, Houston, Texas 77030, and ${ }^{3}$ Department of Psychiatry, Cornell University Medical Center, White Plains, New York 10605

\begin{abstract}
Although much has been learned about the neurobiological mechanisms underlying Pavlovian fear conditioning at the systems and cellular levels, relatively little is known about the molecular mechanisms underlying fear memory consolidation. The present experiments evaluated the role of the extracellular signal-regulated kinase/mitogen-activated protein kinase (ERK/ MAPK) signaling cascade in the amygdala during Pavlovian fear conditioning. We first show that ERK/MAPK is transiently activated-phosphorylated in the amygdala, specifically the lateral nucleus (LA), at $60 \mathrm{~min}$, but not 15, 30, or $180 \mathrm{~min}$, after conditioning, and that this activation is attributable to paired presentations of tone and shock rather than to nonassociative auditory
\end{abstract}

stimulation, foot shock sensitization, or unpaired tone-shock presentations. We next show that infusions of U0126, an inhibitor of ERK/MAPK activation, aimed at the LA, dose-dependently impair long-term memory of Pavlovian fear conditioning but leaves short-term memory intact. Finally, we show that bath application of U0126 impairs long-term potentiation in the LA in vitro. Collectively, these results demonstrate that ERK/MAPK activation is necessary for both memory consolidation of Pavlovian fear conditioning and synaptic plasticity in the amygdala.

Key words: amygdala; fear conditioning; ERK; MAPK; learning; LTP
Considerable evidence has implicated the lateral and basal nuclei of the amygdala (LBA) in the plastic changes underlying acquisition and retention of Pavlovian fear conditioning. Lesion, tract tracing, and electrophysiological studies suggest that fear conditioning involves transmission of sensory information to the lateral nucleus of the amygdala (LA) where alterations in synaptic transmission are thought to encode key aspects of the learning (Fendt and Fanselow, 1999; Maren, 1999; LeDoux, 2000). However, although fear conditioning has received much attention at the systems and cellular levels, relatively little is known about the molecular mechanisms that underlie consolidation of fear memory in the LA.

One relatively recent discovery is the role of the mitogenactivated protein (MAP) family of kinases in synaptic plasticity and memory. These include the p38 MAP kinase (MAPK) and Jun (or stress-activated protein) kinase members, which have been implicated in stress-related cellular responses to injury or inflammation, and also the extracellular signal-regulated kinase (ERK), which has been implicated in cellular growth and differentiation (Kornhauser and Greenberg, 1997; Impey et al., 1999; Oruban et al., 1999). In neurons, ERK/MAPK has been shown to be potently activated by phosphorylation after synaptically driven increases in intracellular $\mathrm{Ca}^{2+}$ (Rosen et al., 1994; Impey et al., 1999). Furthermore, ERK/MAPK has been shown to be activated-phosphorylated in the hippocampus after long-term potentiation (LTP) induction in the Schaffer collateral pathway, an effect that is blocked, along with LTP, by pretreatment with inhibitors of ERK/ MAPK activation (English and Sweatt, 1996, 1997; Impey et al., 1999). Finally, LTP induction in the hippocampus has been shown

\footnotetext{
Received June 23, 2000; revised Aug. 14, 2000; accepted Aug. 15, 2000.

This research was supported in part by National Institute of Mental Health Grants MH 46516, MH 00956, MH 39774, MH 11902, and MH 570161. This work was also supported by grants from the National Alliance for Research on Schizophrenia and Depression and the W. M. Keck Foundation to New York University. We thank Annemieke Schoute for assistance with the histology.

G.E.S., C.M.A., and M.W.S. contributed equally to this work.

Correspondence should be addressed to Dr. Glenn E. Schafe, Center for Neural Science, New York University, 4 Washington Place, Room 809, New York, NY 10003. E-mail: schafe@cns.nyu.edu.

Copyright (C) 2000 Society for Neuroscience $0270-6474 / 00 / 208177-11 \$ 15.00 / 0$
}

to induce the transcription of cAMP response element (CRE)mediated genes, an effect that is prevented by inhibitors of ERK activation (Impey et al., 1998b).

In support of the hypothesis that MAPK regulation is necessary for memory consolidation, several recent studies have demonstrated learning and memory impairments after manipulation of the ERK/MAPK pathway. These include impaired memory consolidation of taste aversion and spatial learning after administration of inhibitors of MAPK activation into the gustatory cortex (Berman et al., 1998) or hippocampus (Blum et al., 1999), respectively. Furthermore, several recent studies have implicated the MAPK signaling pathway in auditory fear conditioning, one using transgenic mice deficient in Ras, an upstream regulator of ERK/ MAPK (Brambilla et al., 1997), and the others using either systemic (Atkins et al., 1998; Selcher et al., 1999) or intracerebroventricular (Schafe et al., 1999) administration of ERK/MAPK inhibitors. However, these studies were limited in that they did not specifically evaluate the role of ERK/MAPK in fear memory consolidation in the amygdala, the presumed locus of memory storage in Pavlovian fear conditioning.

The following series of experiments was aimed at further defining the role of the ERK/MAP kinase signaling pathway in memory consolidation of auditory fear conditioning. We first show that ERK/MAPK is transiently activated in the amygdala after fear conditioning. We next show that pharmacological blockade of ERK/MAPK activation in the amygdala dose-dependently impairs fear memory consolidation. Finally, we show that bath application of an inhibitor of ERK/MAPK activation impairs LTP in the LA in vitro.

\section{MATERIALS AND METHODS}

Subjects. Adult male Sprague Dawley rats (Hilltop Labs, Scottdale, PA) were housed individually in plastic Nalgene cages and maintained on a 12 $\mathrm{hr}$ light/dark cycle. Food and water were provided ad libitum throughout the experiment.

Western blotting. For Western blotting studies, rats were habituated to handling and to the conditioning chamber for $3 \mathrm{~d}$ before training. On the training day, rats received five conditioning trials consisting of a $20 \mathrm{sec}, 5$ $\mathrm{kHz}, 75 \mathrm{~dB}$ tone that coterminated with a $0.5 \mathrm{sec}, 1.0 \mathrm{~mA}$ foot shock. The intertrial interval (ITI) was, on average, $120 \mathrm{sec}$, and the total training time 
lasted 14 min. Control ("Box") rats were handled and exposed to the conditioning box for an equivalent amount of time but were not exposed to tones or shocks. At the appropriate time interval after training, rats were deeply anesthetized with pentobarbital $(100 \mathrm{mg} / \mathrm{kg}$, i.p.) and decapitated. Brains were frozen and stored at $-80^{\circ} \mathrm{C}$ until processed. Amygdala punches were obtained with a $1 \mathrm{~mm}$ punch tool (Fine Science Tools, Foster City, CA) from $400-\mu$ m-thick sections taken on a sliding freezing microtome. The punches included the LA and the basal nucleus and possibly portions of the lateral central nucleus and cortical tissue directly lateral to the external capsule. Punches were briefly sonicated in 100-200 $\mu$ l of ice-cold buffer (20 mM Tris-HCl, pH 7.5, 1 mM EGTA, $1 \mathrm{~mm}$ EDTA, 25 $\mu \mathrm{g} / \mathrm{ml}$ aprotinin, $25 \mu \mathrm{g} / \mathrm{ml}$ leupeptin, $1 \mathrm{~mm}$ sodium pyrophosphate, $500 \mu \mathrm{M}$ phenylmethylsulfonyl fluoride, $4 \mathrm{~mm}$ para-nitrophenyl-phosphate, and 1 $\mathrm{mm}$ sodium orthovanadate). Sample buffer was immediately added to the homogenates, and the samples were boiled at $95^{\circ} \mathrm{C}$ for $10 \mathrm{~min}$. Homogenates were electrophoresed on 10\% SDS-polyacrylamide gels and blotted to Immobilon-P (Millipore, Bedford, MA). Western blots were blocked in TTBS buffer (50 mm Tris- $\mathrm{HCl}, \mathrm{pH} 7.5,150 \mathrm{~mm} \mathrm{NaCl}$, and $0.05 \%$ Tween 20) with $3 \%$ bovine serum albumin and then incubated with an antiphospho-MAPK (1:1000; New England Biolabs, Beverly, MA) or an anti-total MAPK antibody (1:1000; Upstate Biotechnology, Lake Placid, NY). Blots were then incubated with anti-rabbit conjugated to horseradish peroxidase (Cappel, West Chester, PA) and developed using enhanced chemiluminescence (Amersham Pharmacia Biotech, Arlington Heights, IL). Western blots were developed in the linear range used for densitometry. Total protein amounts were determined by a BCA assay for each homogenate. Densitometry was conducted using NIH Image software. To assess for changes in the activation of ERK/MAPK, total kinase levels were first normalized to total protein levels for each sample. Then, activated kinase levels were normalized to total kinase levels. Finally, activated kinase levels in paired rats were expressed as a percentage of those in controls.

Immunohistochemistry. For immunohistochemical studies, rats were habituated to handling and to the conditioning chamber for $3 \mathrm{~d}$ before training. On the training day, rats received five conditioning trials consisting of a $20 \mathrm{sec}, 5 \mathrm{kHz}, 75 \mathrm{~dB}$ tone that coterminated with a $0.5 \mathrm{sec}, 1.0 \mathrm{~mA}$ foot shock (as in the Western blot experiments). At the appropriate time interval, rats were rapidly and deeply anesthetized with pentobarbital (100 $\mathrm{mg} / \mathrm{kg}$, i.p.) and perfused through the heart with ice-cold PBS, followed by ice-cold $4 \%$ paraformaldehyde in $0.1 \mathrm{~m}$ phosphate buffer (PB). Brains were removed and post-fixed in $4 \%$ paraformaldehyde-PB for $24 \mathrm{hr}$ and then cryoprotected in $20 \%$ glycerol-0.1 M PB for $48 \mathrm{hr}$. Immunohistochemistry was performed as described previously (Swank, 2000a,b). Briefly, $30 \mu \mathrm{m}$ free-floating sections through amygdala were obtained using a sliding microtome. Every third section was processed for activated-phosphorylated ERK/MAPK (pMAPK) immunoreactivity. After blocking in Trisbuffered saline (TBS) containing $4 \%$ normal goat serum- $0.2 \%$ Triton $\mathrm{X}-100$, slices were incubated at $4{ }^{\circ} \mathrm{C}$ for $72 \mathrm{hr}$ in anti-phospho-MAPK (rabbit polyclonal antibody, 1:4000; New England Biolabs) in TBS-2\% goat serum- $0.1 \%$ Triton X-100. After extensive washes in TBS, tissue sections were incubated in biotinylated goat anti-rabbit [prediluted; Kirkegaard \& Perry Laboratories (KPL), Gaithersburg, MD] for $2 \mathrm{hr}$ at room temperature. Tissue was again rinsed in TBS followed by incubation in streptavidin-HRP (KPL) at room temperature for $1 \mathrm{hr}$, rinsed in TBS, and developed in cobalt-enhanced DAB (Enhance Black; KPL) for $10 \mathrm{~min}$. Sections were mounted on subbed slides and coverslipped.

Quantification of pMAPK-labeled cells. Sections from comparable anteroposterior levels were selected for scoring, $\sim 3.2-3.3 \mathrm{~mm}$ posterior to bregma. At this level, the LA, central nucleus of amygdala (CE), and basal nuclei are all well represented (Fig. 1E). Cell counts were taken from at least three sections per rat and scored using a defined boundary approximately equivalent to the size of the LA or the CE using either ImagePro (Media Cybernetics, Silver Spring, MD) or NIH Image. Because every third section through the amygdala was processed for immunohistochemistry, it was not necessary to correct for double-counting.

Drugs. In behavioral studies, U0126 (Promega, Madison, WI) was dissolved in $100 \%$ DMSO to a final stock concentration of $4 \mu \mathrm{g} / \mu \mathrm{l}$. For conditioning, the drug was diluted 1:1 in ACSF. U0126 is a specific inhibitor of MAP kinase kinase (MEK), an upstream regulator of ERK/ MAPK activation (Favata et al., 1998). In a recent study using hippocampal homogenates, the effects of U0126 have been shown to be specific to ERK/MAPK and to have no effect at a range of concentrations on other kinases, such as PKA, calcium-calmodulin kinase II, or PKC (Roberson et al., 1999).

Behavioral procedures. Behavioral procedures were conducted as described previously (Schafe et al., 1999; Schafe and LeDoux, 2000). Under Nembutal anesthesia $(45 \mathrm{mg} / \mathrm{kg}$, i.p.), rats were first implanted bilaterally with 26 gauge stainless steel guide cannulas aimed at the LA (for details, see Schafe and LeDoux, 2000). The guide cannulas were fixed to screws in the skull using a mixture of acrylic and dental cement, and a 33 gauge dummy cannula was inserted into each guide to prevent clogging. All surgical procedures were conducted in accordance to the National Institutes of Health Guide for the Care and Use of Experimental Animals and were approved by the New York University Animal Care and Use Committee. Rats were given at least $5 \mathrm{~d}$ to recover before experimental procedures.

On the day before conditioning, rats were habituated to the conditioning chamber and to dummy cannula removal for a minimum of 10-15 min. The following day, rats were given an intra-LBA inf usion of either $0.5 \mu \mathrm{l} 50 \%$ DMSO (vehicle) or one of two doses of U0126 in $50 \%$ DMSO (1.0 or 0.1 $\mu \mathrm{g} /$ side in $0.5 \mu \mathrm{l} ; 0.25 \mu \mathrm{l} / \mathrm{min})$. Injectors remained in the cannulas for 1 min after drug infusion to allow diffusion of the drug from the tip.

Thirty minutes after drug infusions, rats were trained with either a single conditioning trial consisting of a $30 \mathrm{sec}, 5 \mathrm{kHz}, 75 \mathrm{~dB}$ tone that coterminated with a $1.0 \mathrm{sec}, 1.5 \mathrm{~mA}$ foot shock, or with five conditioning trials consisting of a $20 \mathrm{sec}, 5 \mathrm{kHz}, 75 \mathrm{~dB}$ tone that coterminated with a 0.5 sec, $1.0 \mathrm{~mA}$ foot shock (ITI of $120 \mathrm{sec}$ ).

Testing for conditioned fear responses (freezing) in rats conditioned with a single trial were conducted at 1 or $24 \mathrm{hr}$ after conditioning. For each test, rats were placed in a distinctive environment (for details, see Schafe et al., 1999) and exposed to either five or eight conditioned stimulus (CS) tones $(5 \mathrm{kHz}, 75 \mathrm{~dB}, 30 \mathrm{sec})$, respectively. For rats conditioned with five trials, testing occurred at 1, 3, 6 (three tones each test), and 24 (10 tones) hr later $(5 \mathrm{kHz}, 75 \mathrm{~dB}, 20 \mathrm{sec})$. Total seconds freezing during the CS presentations were scored for each rat, and this number was expressed as a percentage of the total CS presentation time. All data were analyzed with ANOVA and Newman-Keuls post hoc $t$ tests. Differences were considered significant if $p<0.05$.

At the end of each behavioral experiment, rats were anesthetized by an overdose of chloral hydrate $(600 \mathrm{mg} / \mathrm{kg})$ and perfused with $10 \%$ buffered formalin. Nissl staining and light microscopy were used to verify the location of the cannula tips within the amygdala.

Slice electrophysiology. Electrophysiological experiments in amygdala slices were conducted as documented previously (for a detailed description, see Weisskopf et al., 1999). Briefly, male Sprague Dawley rats (3-5 weeks old) were deeply anesthetized with halothane, and the brain was rapidly removed and transferred to ice-cold ACSF containing (in $\mathrm{mM}$ ): 115 $\mathrm{NaCl}, 3.3 \mathrm{KCl}, 1 \mathrm{MgSO}_{4}, 2 \mathrm{CaCl}_{2}, 25.5 \mathrm{NaHCO}_{3}, 1.2 \mathrm{NaH}_{2} \mathrm{PO}_{4}, 5$ lactic acid, and 25 glucose, equilibrated with $95 \% \mathrm{O}_{2}-5 \% \mathrm{CO}_{2}$. Coronal slices (400- $\mu \mathrm{m}$-thick) containing the amygdala were cut and recovered in a holding chamber at $32-34^{\circ} \mathrm{C}$ for $30 \mathrm{~min}$ and were then allowed to return to room temperature for at least another $30 \mathrm{~min}$ before recording. An upright microscope equipped with infrared differential interference contrast optics (Olympus Optical, Tokyo, Japan) was used to perform whole-cell patch recordings under visual guidance. Glass recording electrodes were filled with (in mM): $130 \mathrm{~K}$-gluconate, 0.6 EGTA, $2 \mathrm{MgCl}_{2}, 5 \mathrm{KCl}, 10 \mathrm{HEPES}, 2$ $\mathrm{Mg}$-ATP, and $0.3 \mathrm{Na}_{3}$-GTP, $\mathrm{pH} 7.3$ (290-300 mOsm). The electrodes typically had resistances of $4-8 \mathrm{M} \Omega$. All cells were allowed to remain at their resting potentials.

Stimuli (150 $\mu$ sec duration) were delivered through bipolar stainless steel electrodes placed in the ventral striatum, just medial to the dorsal lateral amygdala (LAd). This stimulating protocol activates fibers that originate, at least in part, in the auditory thalamus (LeDoux et al., 1990; Weisskopf et al., 1999). The stimulation intensity was kept at a minimum and adjusted for each cell (between 80 and $140 \mu \mathrm{A}$ ) to produce a reliable EPSP without also recruiting polysynaptic responses or spiking. Baseline responses were monitored at $0.1 \mathrm{~Hz}$. After stabilization of baseline responses, LTP was induced by pairing trains of 10 stimuli at $30 \mathrm{~Hz}$ with 1 $\mathrm{nA}, 5 \mathrm{msec}$ depolarizations given 5-10 msec after the onset of each EPSP in the train. This pattern of stimulation yields an action potential at the peak of each EPSP of the train. This pairing was given 15 times at $10 \mathrm{sec}$ intervals. For each cell, the stimulation intensity for LTP induction was the same as that used to elicit baseline EPSPs.

Picrotoxin $(75 \mu \mathrm{M})$ was included in the bath in all experiments to block fast GABAergic transmission but was not observed to produce epileptiform bursting in the amygdala. Drugs were made up in DMSO stock solution and diluted 1000 times into the superfusing ACSF, yielding a final concentration of U0126 of $10 \mu \mathrm{M}$. In control experiments, slices were superfused with $0.1 \%$ DMSO vehicle. The addition of U0126 to the bath was not observed to affect membrane potential $\left(V_{\mathrm{m}}\right.$ vehicle, $-71.38 \pm 1.75$; $\left.V_{\mathrm{m}} \mathrm{U} 0126,-70.39 \pm 0.86\right)$.

In all experiments, the slope of the EPSP was measured, and LTP for each time point was expressed as a percentage of the preinduction baseline. Data were analyzed with ANOVA and Newman-Keuls post hoc $t$ tests.

\section{RESULTS \\ ERK/MAPK is transiently activated in the amygdala after Pavlovian fear conditioning}

Previous studies have shown that ERK/MAPK is activated in the hippocampus after Pavlovian fear conditioning (Atkins et al., 1998). Other recent studies have shown activation of ERK/MAPK in insular cortex and hippocampus after either taste aversion (Berman et al., 1998; Swank, 2000a) or spatial learning (Blum et al., 1999), respectively. Given the well established role of the LBA in fear conditioning, our first objective was to determine whether ERK/MAPK is similarly activated in the LBA and whether this activation is characterized by a specific time course. For this series of experiments, we first used Western immunoblotting techniques to quantify total amounts of activated ERK/MAPK from amygdala 


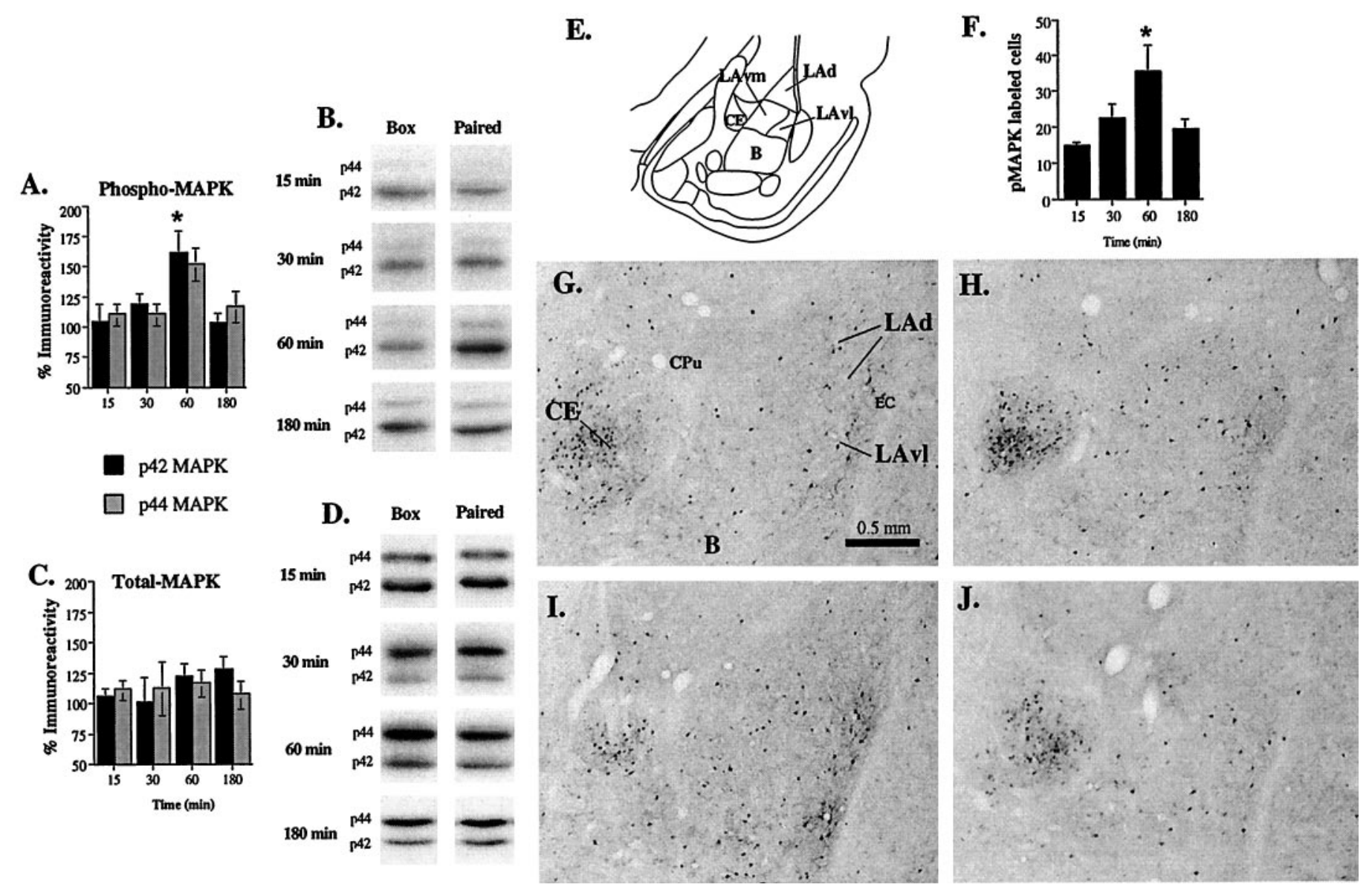

Figure 1. Time course of ERK/MAPK activation in the amygdala. $A$, Mean \pm SE percent pMAPK immunoreactivity from amygdala punches taken from rats decapitated at $15(n=10), 30(n=10), 60(n=14)$, or $180(n=10)$ min after conditioning. Rats were presented with five tone-foot shock pairings. Paired samples in each group were normalized relative to sham-trained (Box) controls (for details, see Materials and Methods). p42 and p44 correspond to the molecular weights (in kilodaltons) of the two isoforms of mammalian ERK (ERK1 and ERK2) that are recognized by the pMAPK antibody. * $p<$ 0.05 relative to the 15 min time point. $B$, Representative pMAPK blots from Box and Paired conditions at different time points after conditioning. $C$, Mean \pm SE percent tMAPK immunoreactivity at different time points after conditioning $(15,30,60$, or 180 min) from the samples in $A$. Paired samples in each group were normalized relative to sham-trained (Box) controls. D, Representative tMAPK blots from Box and Paired conditions at different time points after conditioning. $E$, Schematic of the amygdala at approximately bregma -3.3 (according to Paxinos and Watson, 1997). $F$, Mean \pm SE pMAPK-immunoreactive cells in the LA at $15(n=5), 30(n=5), 60(n=5)$, or $180(n=5)$ min after conditioning. Rats were presented with five tone-foot shock pairings. ${ }^{*} p<0.05$ relative to the 15 min time point. $G$, Representative photomicrograph of pMAPK labeling in the amygdala at 15 min after conditioning. $C P u$, Caudate/putamen; $E C$, external capsule. $H$, Representative photomicrograph of pMAPK labeling in the amygdala at 30 min after conditioning. I, Representative photomicrograph of pMAPK labeling in the amygdala at 60 min after conditioning. $J$, Representative photomicrograph of pMAPK labeling in the amygdala at 180 min after conditioning.

tissue punches. Next, we used immunohistochemistry to anatomically localize expression of activated ERK/MAPK to particular amygdala nuclei. For each experiment, we used an antibody that recognizes activated-phosphorylated ERK/MAPK (pMAPK). To control for total amount of ERK protein, Western blot experiments also used an antibody that recognizes total (both phosphorylated and unphosphorylated) ERK/MAPK (tMAPK). For these experiments, we attempted to strike a balance between giving enough conditioning trials to observe significant regulation of ERK/ MAPK with our biochemical methods (Atkins et al., 1998) but not so many that we would be unable to chart a time course of ERK/MAPK activation. Thus, we settled on five tone-shock pairings given over the course of $14 \mathrm{~min}$.

\section{Western blotting}

Results of the Western blotting can be viewed in Figure $1 A-D$ in which both histograms for both pMAPK and tMAPK immunoreactivity can be found (Fig. $1 A, C$ ), as well as representative blots from both trained (Paired) and sham-trained (Box) controls (Fig. $1 B, D)$. For this latter group, rats were handled and exposed to the conditioning box for an equivalent amount of time but were not exposed to tones or shocks. Fear conditioning resulted in significant increases in pMAPK immunoreactivity for both p42 and p44
ERK/MAPK at 60 min after training but not at other time points. The ANOVA (kinase by time point) for pMAPK scores revealed a significant effect for time point $\left(F_{(3,80)}=5.66 ; p<0.01\right)$. The effect for kinase $\left(F_{(1,80)}=0.33\right)$ and the interaction $\left(F_{(3,80)}=0.79\right)$ were not found to differ. Newman-Keuls post hoc $t$ tests revealed that differences existed between 15 and 60 min time points for the p42 kinase $(p<0.05)$. No significant differences were detected between other time points. Furthermore, this increase was not accounted for by changes in total ERK/MAPK (Fig. $1 C, D)$ ). Here, the ANOVA showed a nonsignificant effect of kinase $\left(F_{(1,80)}=0.14\right)$, time point $\left(F_{(3,80)}=0.53\right)$, and interaction $\left(F_{(3,80)}=0.83\right)$. Thus, ERK/MAPK is transiently activated in the amygdala after fear conditioning, with a peak at $60 \mathrm{~min}$.

\section{Immunohistochemistry}

The transient increase in pMAPK as assessed by Western blotting was confirmed by immunohistochemistry (Fig. $1 E-J$ ). Representative photomicrographs of pMAPK labeling are presented in Figure $1 G-J$, and cell counts of pMAPK-labeled cells in the LA are presented in Figure $1 F$. pMAPK-labeled cells were found scattered throughout the LA, particularly in the ventral portions of LAd and ventrolateral lateral amygdala (LAvl). There were also scattered labeled cells in ventromedial lateral amygdala (LAvm). pMAPK 

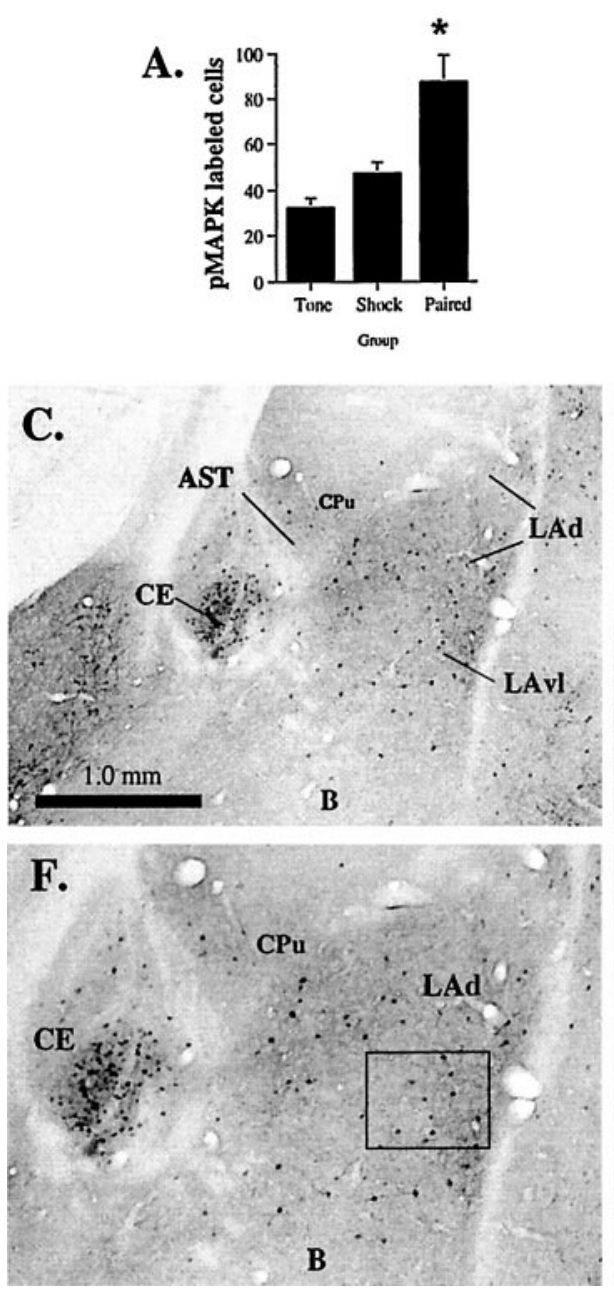
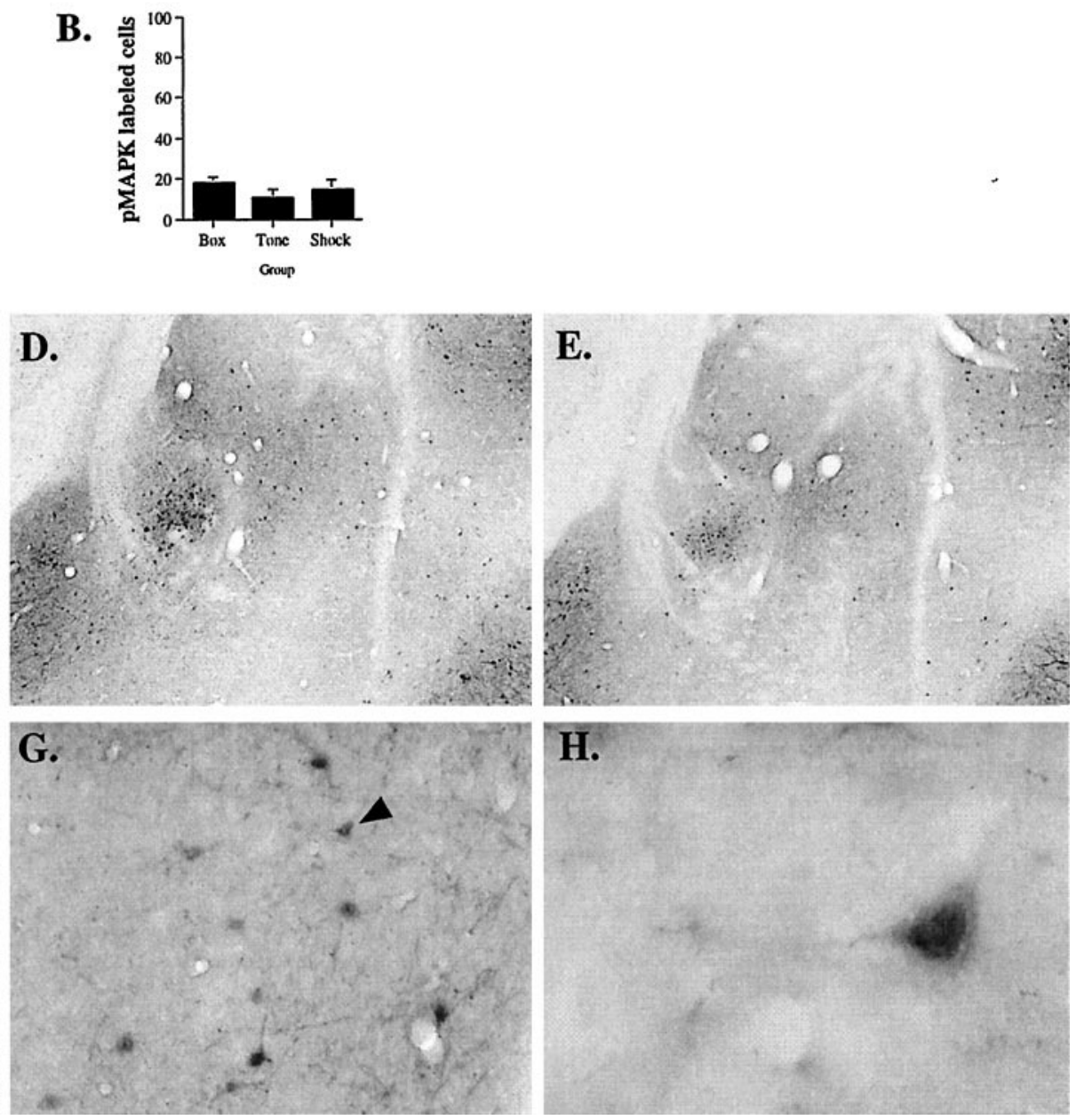

Figure 2. Pairing specificity of ERK/MAPK activation in the LA. $A$, Mean \pm SE pMAPK-immunoreactive cells in the LA after presentation of tone alone (Tone; $n=5)$, foot shock alone (Shock; $n=5)$, or tone-foot shock pairings (Paired; $n=5)$. Rats were given five presentations of each stimulus and perfused 60 min later. ${ }^{*} p<0.05$ relative to the other groups. $B$, Mean \pm SE pMAPK-immunoreactive cells in the LA after box alone $(B o x ; n=3)$, tone alone (Tone; $n=3$ ), or foot shock alone (Shock; $n=3$ ). Rats were perfused 60 min after treatment. $C$, Representative photomicrograph of pMAPK labeling in the amygdala after conditioning. $A S T$, Amygdala/striatal transition zone. $D$, Representative photomicrograph of pMAPK labeling in the amygdala after foot shock alone. $E$, Representative photomicrograph of pMAPK labeling in the amygdala after tone alone. $F, 10 \times$ magnification of $\mathrm{pM}$ APK labeling in the LA and surrounding nuclei from $C$. $G, 40 \times$ magnification of pMAPK labeling in the LA from the inset in $F$. $H, 100 \times$ magnification of pMAPK labeling in an LA pyramidal cell (from $G$; arrow), showing nuclear labeling.

labeling was also observed in the adjacent $\mathrm{CE}$. Both the basal nucleus of amygdala (B) and cortical areas just lateral to the LA, however, had few pMAPK-labeled cells. We therefore counted cells only within the LA (including LAd, LAvl, and LAvm) and CE for statistical analysis.

Consistent with the results of the Western blotting, increases in pMAPK labeling in the LA were most prominent at the $60 \mathrm{~min}$ time point. An ANOVA for cell counts in the LA found an overall significant difference between groups $\left(F_{(3,18)}=3.76 ; p<0.05\right)$, with a significant difference between 15 and $60 \mathrm{~min}$ time points $(p<0.05$; Newman-Keuls). In contrast, expression of pMAPK in the CE did not differ across time points: $15 \mathrm{~min}, 21.2 \pm 5.2 ; 30 \mathrm{~min}$, $21.5 \pm 6.4 ; 60 \mathrm{~min}, 23.2 \pm 5.1 ; 180 \mathrm{~min}, 23.0 \pm 4.3\left(F_{(3,15)}=0.03\right.$; $p>0.05)$. Thus, the activation of ERK/MAPK in the amygdala at $60 \mathrm{~min}$ appears to be localized to the LA.

\section{Activation of ERK/MAPK in the LA is specific to associative tone-shock pairing}

In the previous experiments, we showed using both Western blot and immunohistochemistry that ERK/MAPK is transiently activated in the LA at 60 min after fear conditioning. In this series of experiments, we used immunohistochemical methods to evaluate whether activation of ERK/MAPK in the LA is specific to paired presentations of tone and shock or is attributable to nonassociative factors such as auditory stimulation or foot shock sensitization. Rats in this series of experiments were given one of three types of stimulation, followed 60 min later by perfusion: five tone-shock pairings, five tones without shocks, or five shocks without tones.

Results can be viewed in Figure $2 A-H$. As in the first series of experiments, we observed pMAPK labeling throughout the LA and $\mathrm{CE}$ at $60 \mathrm{~min}$ after fear conditioning, although labeling in the basal nucleus and adjacent cortex was low. As before, labeling in the LA appeared to be most prominent in the ventral portions of LAd and also in LAvl. There were also a few labeled cells in LAvm. Representative photomicrographs from each group can be viewed in Figure $2 C-E$, and higher magnification photomicrographs from a paired rat are presented in Figure $2 F-H$. Cell counts from the LA (including LAd, LAvl, and LAvm) can be viewed in Figure $2 A$. Statistical analysis on cell counts revealed that pMAPK labeling was significantly increased in the LA in paired animals relative to tone alone or shock alone conditions. The ANOVA revealed a significant effect for group $\left(F_{(2,12)}=12.03, p<0.01\right)$, with the paired group being significantly different from the others $(p<0.05$; Newman-Keuls test). There were no significant differences between tone alone and shock alone groups.

Because rats in this experiment were not run against a nonstimulated control, it is not possible to evaluate whether the labeling 
observed in tone alone and shock alone groups reflects basal levels of ERK/MAPK activation in the LA or increases relative to this baseline. Thus, it may be argued that the increase in pMAPK labeling observed in the LA after tone-shock pairings is simply attributable to an additive effect of separate cells responsive to tone and shock alone. To evaluate this possibility, we ran an additional assay, comparing pMAPK labeling in the LA in rats receiving sham training (box only), tone alone, or foot shock alone. Results can be viewed in Figure $2 B$. It is evident from the figure that no differences existed between groups. The ANOVA showed no significant effects $\left(F_{(2,6)}=2.75\right)$. Thus, the levels of pMAPK labeling observed after presentations of tones or shocks alone appear to reflect basal levels of ERK/MAPK activation, which suggests that the increase in pMAPK labeling observed in the LA is not likely to be attributable to an additive effect of tone- and shock-responsive cells. Rather, the increase in pMAPK observed in the LA appears to be specific to pairing of tone and shock.

To specifically evaluate the associative specificity of pMAPK labeling in the LA, we next examined activation of ERK/MAPK in the LA after unpaired presentations of tone and shock (Schafe et al., 1999). Rats in this experiment were handled and habituated to the conditioning context for $3 \mathrm{~d}$ as in previous experiments. On the training day, rats received either five paired presentations of tone and shock (as in the previous experiments) or five unpaired toneshock presentations. For this latter group, the unconditioned stimulus (US) shock preceded the tone CS by $60 \mathrm{sec}$, and at least 120 sec were allowed to pass between a tone CS presentation and the next trial. Rats in each group were killed by perfusion 60 min after stimulation, and brains were processed using immunohistochemistry. Results can be viewed in Figure 3. Relative to unpaired controls, rats in the paired condition were observed to have significantly more labeled cells in the LA (including LAd, LAvl, and LAvm $)\left(t_{(8)}=2.48, p<0.05\right)$. The percent increase in labeling in paired rats $(\sim 30 \%)$ appeared to be somewhat less than that in the previous experiment in which paired rats were compared with rats receiving shock alone, which could reflect the fact that unpaired presentations of tone and shock produce less, but not necessarily no, learning about the tone (Schafe et al., 1999). Nonetheless, activation of ERK/MAPK in the LA appears to be specific to associative pairing of tone and shock rather than reflecting nonassociative processes.

Interestingly, rats receiving shock alone stimulation were not observed to have increases in PMAPK in the LA, which might, for example, be expected to accompany contextual fear conditioning. This result stands in contrast to the findings of other recent studies in the fear conditioning literature that have shown regulation of transcription factors such as early growth response gene 1 in the amygdala, and particularly the LA, after contextual fear conditioning (Rosen et al., 1998; Malkani and Rosen, 2000). However, the relative lack of pMAPK labeling after shock presentation in the present study may be a result of at least two factors. First, it may be possible that the time course of ERK/MAPK activation after contextual learning is different from that after auditory fear conditioning. Second, because rats in our labeling experiments received extensive preexposure to the conditioning apparatus $(3 \mathrm{~d})$ before stimulation, it is possible that latent inhibition may have obscured any potential context learning and accompanying regulation of ERK/MAPK. Future experiments using different training protocols will be necessary to determine whether contextual fear conditioning is also characterized by increases in ERK/MAPK activation in the amygdala and whether the pattern of expression is similar to that after auditory fear conditioning.

\section{Pharmacological blockade of ERK/MAPK activation in the amygdala impairs fear memory consolidation}

The previous experiments showed that ERK/MAPK is transiently activated in the amygdala and that this activation is specific to associative pairing of tone and shock. In the next series of experiments, we asked whether ERK/MAPK activation in the LBA is obligatory for fear memory consolidation. Several recent studies
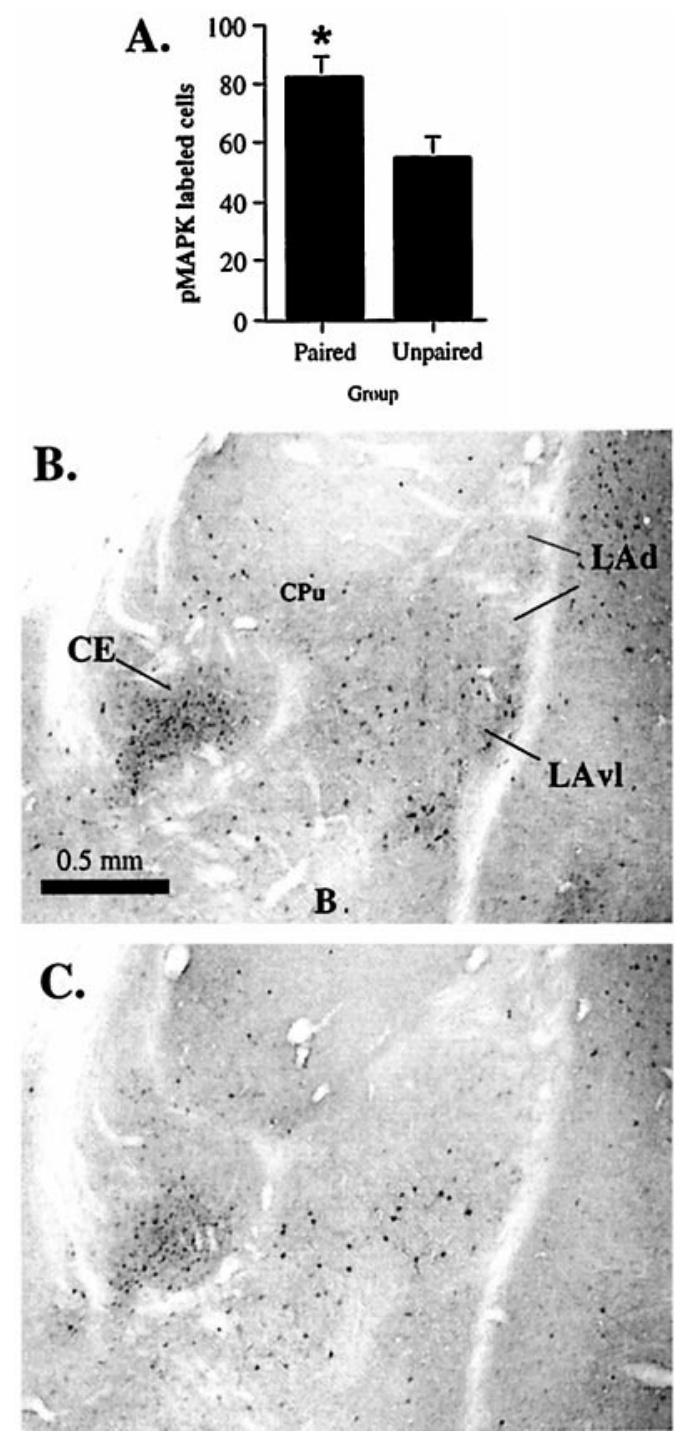

Figure 3. Associative specificity of ERK/MAPK activation in the LA. A, Mean \pm SE pMAPK-immunoreactive cells in the LA after paired (Paired; $n=5$ ) or unpaired (Unpaired; $n=5$ ) presentations of tone and shock. Rats were perfused 60 min later. ${ }^{*} p<0.05$ relative to the unpaired group. $B$, Representative photomicrograph of pMAPK labeling in the amygdala after paired stimulation. $C$, Representative photomicrograph of pMAPK labeling in the amygdala after unpaired stimulation.

using either systemic (Atkins et al., 1998; Selcher et al., 1999) or intracerebroventricular (Schafe et al., 1999) pharmacological manipulations have implicated the ERK/MAPK signaling pathway in fear conditioning in rodents. To date, however, no study has targeted these manipulations to the amygdala. Thus, in the present experiments, rats received bilateral intra-amygdala infusions of different doses of U0126, a specific inhibitor of MEK, an upstream regulator of ERK/MAPK activation (Favata et al., 1998). In these experiments, rats were infused with U0126 or vehicle before fear conditioning and assessed for retention of fear memory at various time points thereafter. Although the LA was the main target, our inf usions also likely affected the adjacent basal nucleus. We therefore refer to the affected area as the LBA.

In the first series of experiments, rats were given single-trial Pavlovian fear conditioning, a protocol that matches that of previous reports from our laboratory (Schafe et al., 1999; Schafe and LeDoux, 2000). For this series of experiments, rats were tested for fear retention at either 1 or $24 \mathrm{hr}$ after conditioning (Fig. 4A). In the second series of experiments, rats were given five-trial Pavlovian fear conditioning, a protocol that was identical to that used in the Western blot and immunohistochemical experiments reported 


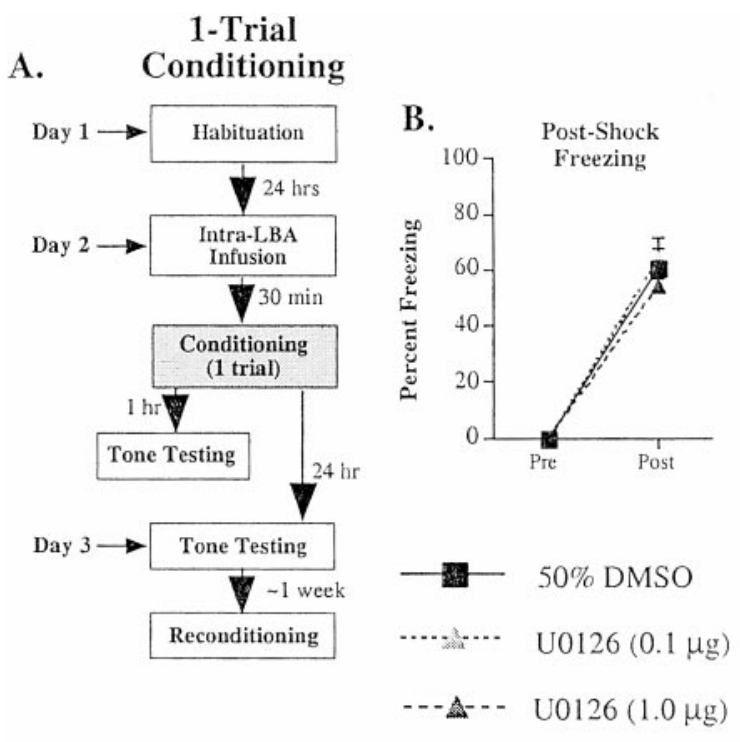

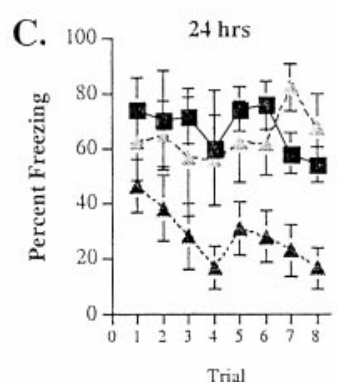

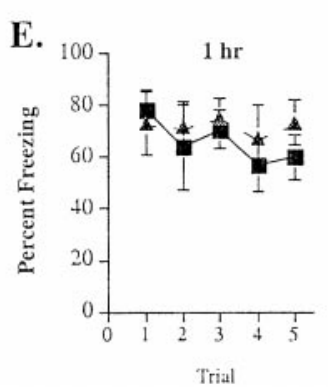

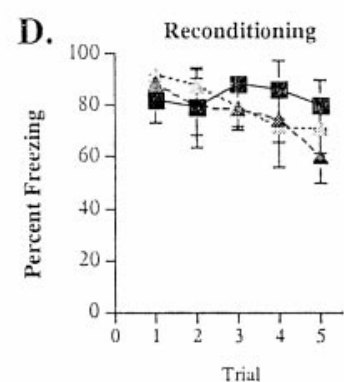

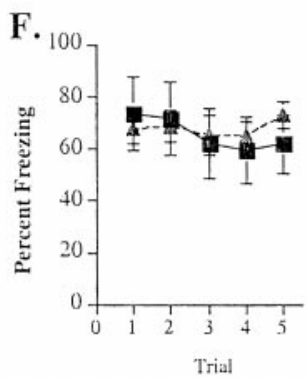

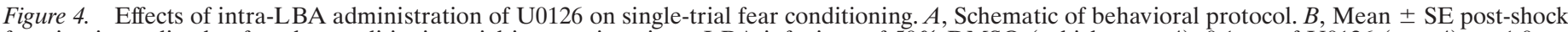

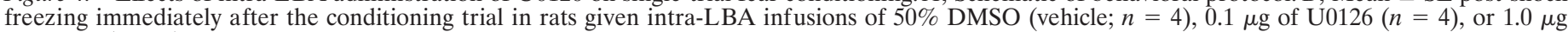

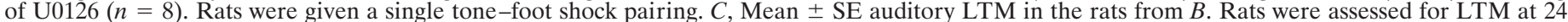

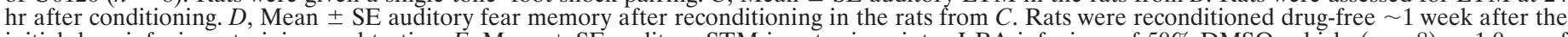

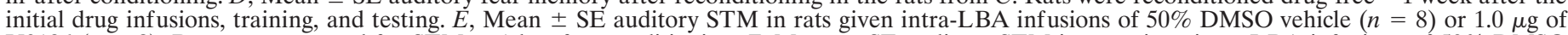

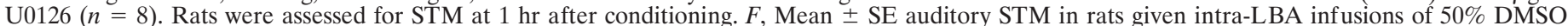
vehicle $(n=6)$ or $1.0 \mu \mathrm{g}$ of U0126 $(n=6) 24 \mathrm{hr}$ before conditioning and STM testing (see adjacent schematic of behavioral procedures).

earlier in this paper. For this series of experiments, rats were tested for fear retention at 1, 3, 6, and $24 \mathrm{hr}$ after training (Fig. 5A). Finally, we evaluated the effectiveness of U0126 at blocking ERK/ MAPK activation in the LBA. For this experiment, rats were given infusions of different doses of U0126 $(1.0$ or $0.1 \mu \mathrm{g})$ or vehicle 30 min before five-trial fear conditioning and killed $1 \mathrm{hr}$ later. Punches from the LBA surrounding the cannula tips were subjected to ERK/MAPK immunoblotting.

\section{Single-trial learning}

Results of the one-trial conditioning can be viewed in Figure $4 B-F$. Infusions of U0126 had no effect on post-shock freezing (Fig. 4B), suggesting that foot shock sensitivity was not disrupted by the drug. The ANOVA (drug dose $\times$ trial) showed an effect only for trials $\left(F_{(1,13)}=336.6 ; p<0.01\right)$. The effects for dose $\left(F_{(2,13)}=0.89\right)$ and interaction $\left(F_{(2,13)}=0.89\right)$ were not significant. Twenty four hours later, however, rats treated with U0126 showed a dose-dependent impairment of long-term memory (LTM) to the tone (Fig. 4C). The ANOVA (dose $\times$ trial) for LTM scores revealed a significant effect for group (drug dose; $F_{(2,13)}=5.54 ; p<0.02$ ). The effects for trials $\left(F_{(7,91)}=1.72\right)$ and interaction $\left(F_{(14,91)}=1.27\right)$ were not significant. Newman-Keuls post hoc $t$ tests revealed that significant differences existed between vehicle controls and the high dose of U0126 on trials three through eight $(p<0.05)$, although no differences existed between vehicle controls and the low dose on any trial. Thus, long-term retention of Pavlovian fear memory is dose-dependently disrupted by U0126, which suggests that activation of ERK/MAPK is necessary for fear memory consolidation.

To control for possible nonspecific effects of U0126 on sensory or performance factors related to fear memory, three additional experiments were conducted. First, rats in the previous experiment were reconditioned drug-free $\sim 1$ week later and were able to reacquire normal levels of fear (Fig. $4 D$ ). The ANOVA (dose $\times$ trials) revealed only an effect for trials $\left(F_{(4,52)}=2.89 ; p<0.05\right)$. The effects for dose $\left(F_{(2,13)}=0.19\right)$ and interaction $\left(F_{(8,52)}=0.93\right)$ were not found to be significant. Thus, inf usions of U0126 did not appear to result in damage to the amygdala that might account for the inability of rats to retain fear memories over the course of $24 \mathrm{hr}$. Second, separate groups of rats injected with the highest dose of
U0126 $(1.0 \mu \mathrm{g})$ or vehicle before training were shown to have intact short-term memory (STM) for the tone $1 \mathrm{hr}$ after training (Fig. $4 E$ ). The ANOVA (dose $\times$ trials) showed a nonsignificant effect of dose $\left(F_{(1,14)}=0.13\right)$, trials $\left(F_{(4,56)}=1.58\right)$, or interaction $\left(F_{(4,56)}=\right.$ 1.19). Thus, U0126 did not appear to produce deficits in tone sensitivity during training or to affect the formation of LTM by impairing shorter forms of synaptic plasticity in the LBA. Third, infusion of the highest dose of U0126 $24 \mathrm{hr}$ before conditioning had no effect on the expression of STM 1 hr after training, which was assessed at approximately the same time as LTM in the previous experiment (Fig. $4 F$ ). The ANOVA (dose $\times$ trials) showed a nonsignificant effect of dose $\left(F_{(1,10)}=0.03\right)$, trials $\left(F_{(4,40)}=1.36\right)$, or interaction $\left(F_{(4,40)}=1.12\right)$. Thus, it is unlikely that the freezing deficits observed in the LTM test (Fig. $4 C$ ) are attributable to some nonspecific effect of U0126 on general activity levels (i.e., hyperactivity) that might compete with normal behavioral expression 24 $\mathrm{hr}$ after the infusion. Collectively, these findings strongly favor the conclusion that U0126 impairs fear memory retention by blocking memory consolidation processes.

\section{Multiple-trial learning}

In the previous behavioral experiments, the effects of U0126 were evaluated using single-trial fear conditioning methods. Although matching that of previous behavioral protocols used in our laboratory (Schafe et al., 1999; Schafe and LeDoux, 2000), it failed to directly match the five-pairing training protocol used in the Western blot and immunohistochemical experiments reported earlier in the paper. Furthermore, STM and LTM were assayed in different rats. Thus, in the next series of experiments, rats were treated with multiple doses of U0126 before multiple-trial Pavlovian fear conditioning (five CS-US pairings). This training protocol matched exactly that of the one used in the Western blot and immunohistochemical experiments (Figs. 1-3). Additionally, we extended our testing protocol to include multiple memory tests within the same rats both on the day of training and $24 \mathrm{hr}$ later to ascertain the time course of the amnesic effects of U0126 (Fig. 5A).

Figure $5 B$ depicts suppression of ERK/MAPK activation by multiple doses of U0126. The ANOVA (dose $\times$ kinase) revealed a significant effect for dose $\left(F_{(2,40)}=54.74 ; p<0.01\right)$ and a nonsig- 


\section{B.}
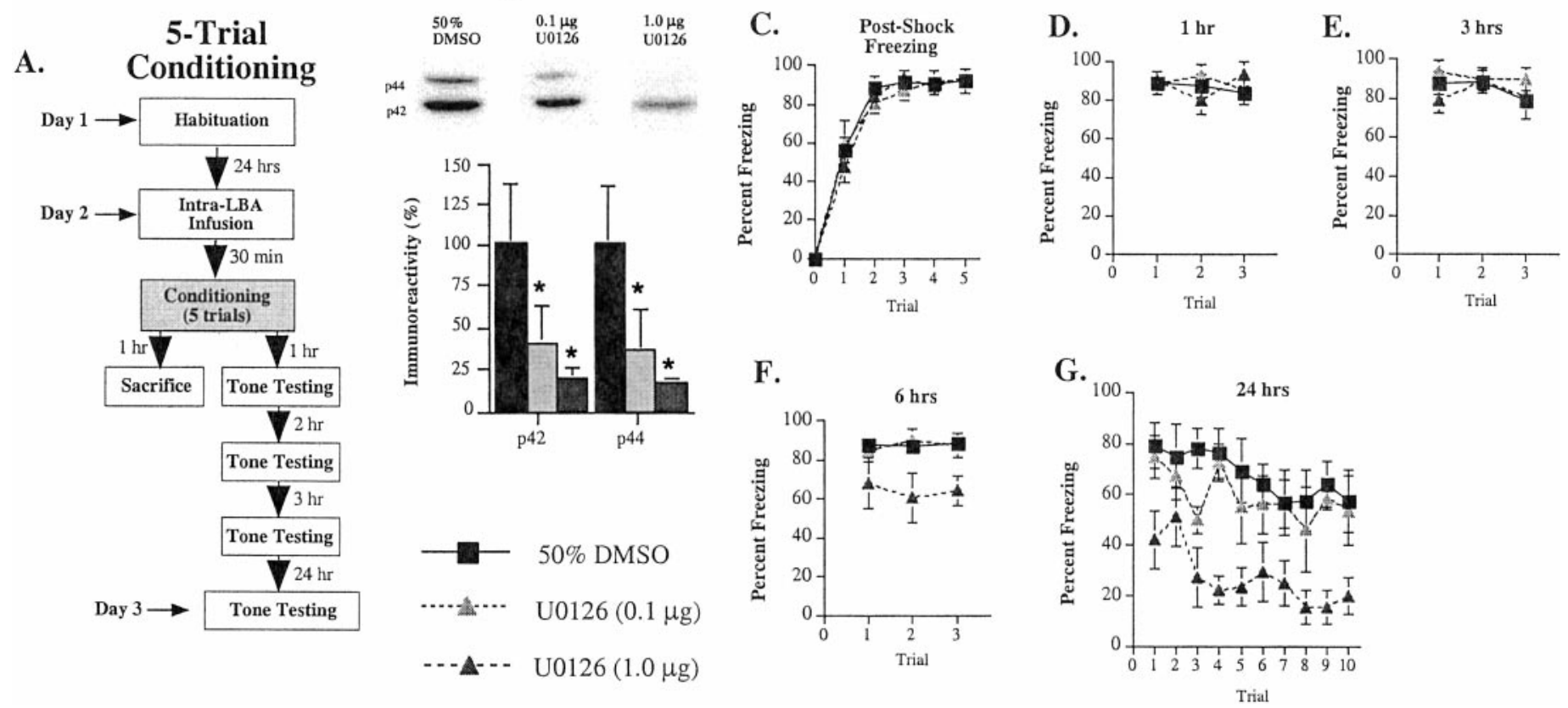

Figure 5. Effects of intra-LBA administration of U0126 on multiple-trial fear conditioning. $A$, Schematic of behavioral protocol. $B$, Representative blots and mean \pm SE percent pMAPK immunoreactivity from amygdala punches taken from rats given intra-LBA infusions of $50 \%$ DMSO (vehicle; $n=6$ ), $0.1 \mu \mathrm{g}$ of U0126 $(n=6)$, or $1.0 \mu \mathrm{g}$ of U0126 $(n=6)$. ${ }^{*} p<0.05$ relative to vehicle controls. $C$, Mean \pm SE post-shock freezing between conditioning trials in rats given intra-LBA inf usions of 50\% DMSO (vehicle; $n=8), 0.1 \mu \mathrm{g}$ of U0126 $(n=4)$, or $1.0 \mu \mathrm{g}$ of U0126 $(n=7)$. Rats were given five tone-foot shock pairings. $D$, Mean $\pm \mathrm{SE}$ auditory fear memory assessed at $1 \mathrm{hr}$ after conditioning in the rats from $C$. E, Mean \pm SE auditory fear memory assessed at $3 \mathrm{hr}$ after conditioning in the rats from $C . F$, Mean $\pm \mathrm{SE}$ auditory fear memory assessed at $6 \mathrm{hr}$ after conditioning in the rats from $C$. $G$, Mean $\pm \mathrm{SE}$ auditory fear memory assessed at $24 \mathrm{hr}$ after conditioning in the rats from $C$.

nificant effect for trials $\left(F_{(1,40)}=0.05\right)$ or interaction $\left(F_{(2,40)}=\right.$ $0.01)$. Newman-Keuls post hoc $t$ tests revealed that both drug doses significantly reduced pMAPK immunoreactivity relative to vehicle controls and that no significant differences existed between the drug doses.

Consistent with the findings of the one-trial conditioning experiment, post-shock freezing was not affected by U0126 (Fig. 5C). The ANOVA showed only a significant effect of trials $\left(F_{(4,64)}=\right.$ 32.57; $p<0.01)$. Thus, as before, the drug did not appear to affect foot-shock sensitivity. The effects for group $\left(F_{(2,16)}=0.50\right)$ and interaction $\left(F_{(8,64)}=0.56\right)$ were not significant. Also consistent with the previous behavioral experiments, STM assessed either 1 or $3 \mathrm{hr}$ later was found to be intact (Fig. $5 D, E$ ). The ANOVA (dose $\times$ trials) for fear memory at $1 \mathrm{hr}$ showed a nonsignificant effect of dose $\left(F_{(2,16)}=0.15\right)$, trials $\left(F_{(2,32)}=0.64\right)$, or interaction $\left(F_{(4,32)}=1.98\right)$ and the ANOVA for fear memory at $3 \mathrm{hr}$ showed a similar nonsignificant effect of dose $\left(F_{(2,16)}=1.38\right)$, trials $\left(F_{(2,32)}=\right.$ $1.67)$, or interaction $\left(F_{(4,32)}=0.68\right)$. However, at $6 \mathrm{hr}$ after conditioning, differences began to emerge in the group treated with the highest dose of U0126 (Fig. 5F). The ANOVA for fear memory at $6 \mathrm{hr}$ revealed a significant effect of dose $\left(F_{(2,16)}=5.40 ; p<0.05\right)$ and a nonsignificant effect for trials $\left(F_{(2,32)}=0.02\right)$ or interaction $\left(F_{(4,32)}=0.19\right)$. This difference became more pronounced the following day (Fig. $5 G$ ). The ANOVA for LTM scores revealed a significant effect for group $\left(F_{(2,16)}=9.22 ; p<0.01\right)$ and trials $\left(F_{(9,144)}=3.21 ; p<0.01\right)$ but not interaction $\left(F_{(18,144)}=0.63\right)$. Furthermore, Newman-Keuls post hoc $t$ tests revealed that significant differences existed between vehicle controls and rats infused with the highest dose of U0126 on every trial but the second $(p<$ $0.05)$. No differences were detected between vehicle controls or the low dose of U0126 on any trial. Thus, intra-LBA administration of U0126 dose-dependently impairs both ERK/MAPK activation and fear memory consolidation.

\section{Histology}

Histological verification of cannula placements can be viewed in Figure $6 A-D$ (see figure legend for details). Cannula tips were observed to lie throughout the LBA at various rostrocaudal levels. Only rats with cannula tips at or within the boundaries of the LBA were included in the data analysis.

\section{In vitro application of inhibitors of ERK/MAPK activation to the amygdala impairs long-term potentiation in the LA}

Previous studies using both in vivo and in vitro recording methods have demonstrated LTP in the LA after stimulation of auditory afferent pathways (Chapman et al., 1990; Clugnet and LeDoux, 1990; Rogan and LeDoux, 1995; Huang and Kandel, 1998; Weisskopf et al., 1999). Furthermore, neural activity in the LA has been shown to be modified during auditory fear conditioning in a manner similar to that observed after artificial LTP induction (McKernan and Shinnick-Gallagher, 1997; Rogan et al., 1997). This pattern of findings suggests that an LTP-like process in the LA may underlie fear conditioning. If true, then amygdala LTP should be impaired, like fear memory consolidation, by inhibitors of ERK/ MAPK activation. To evaluate this hypothesis, we next used an in vitro slice preparation to induce LTP in the LA with or without bath application of U0126. In these experiments, we measured LTP at "thalamic" input synapses to the LA by placing stimulating electrodes in the ventral striatum, which contains fibers originating in the auditory thalamus traveling en route to the LA (LeDoux et al., 1990) (Fig. 7A). Consistent with other studies in our lab, we induced "associative" LTP by pairing trains of presynaptic stimulation with depolarizations of the postsynaptic cell (Weisskopf et al., 1999). This method has been shown to be effective at enhancing EPSPs between pairs of neocortical neurons (Markram et al., 1997). Furthermore, because fear conditioning is thought to involve convergence of auditory and nociceptive inputs onto single neurons in the LA, this induction protocol may have distinct advantages over traditional tetanic stimulation because pairing is more consistent with the cellular mechanisms thought to underlie natural associative learning (Weisskopf et al., 1999).

Results can be viewed in Figure $7 B$ in which the mean $\pm \mathrm{SE}$ slope of the EPSP (relative to baseline) for each group is presented, as well as representative traces for each group from an individual 
A.

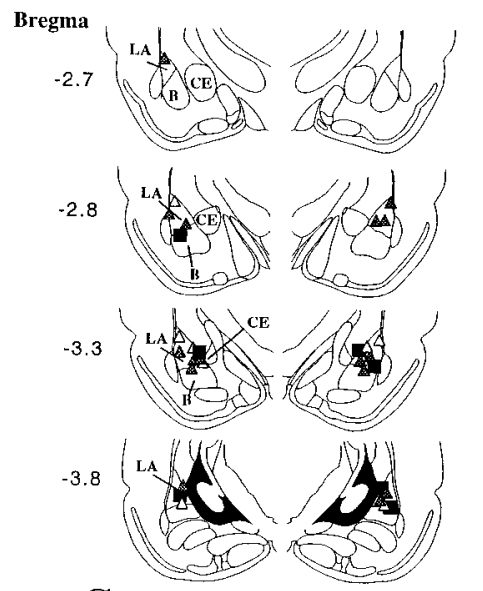

C.
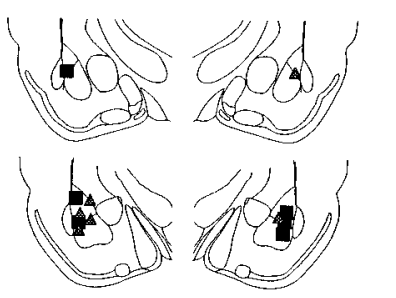

(n)
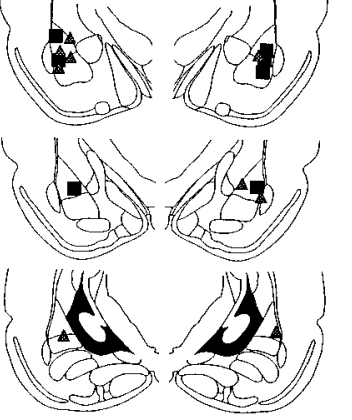

B.

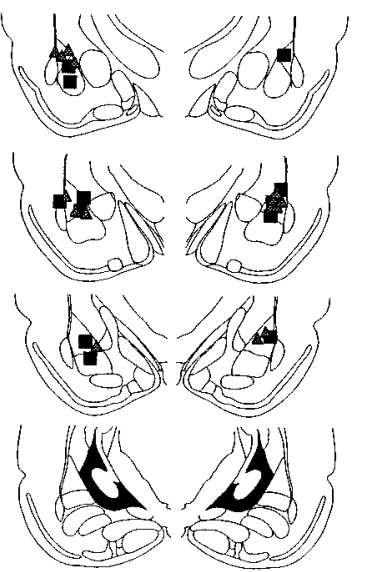

D.

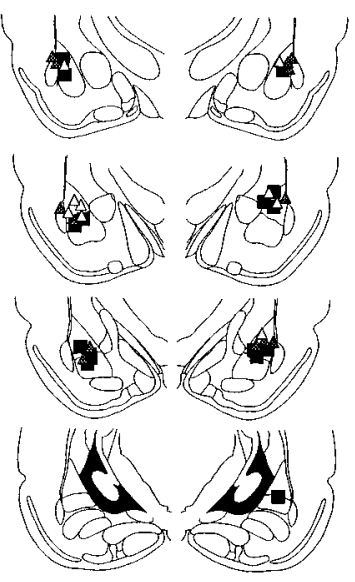

Figure 6. Histological verification of cannula placements. $A$, Cannula tip placements from rats trained with a single pairing and tested for LTM 24 hr later (see Fig. 4B-D). Rats were infused with ACSF (black squares), 0.1 $\mu \mathrm{g}$ of U0126 (white triangles), or $1.0 \mu \mathrm{g}$ of U0126 (dark gray triangles). $B$, Cannula tip placements from rats trained with a single pairing and tested for STM $1 \mathrm{hr}$ later (see Fig. 4E). Rats were infused with ACSF (black squares) or $1.0 \mu \mathrm{g}$ of U0126 (dark gray triangles). C, Cannula tip placements from rats trained with a single pairing and tested for STM $1 \mathrm{hr}$ later (see Fig. $4 F$ ). Rats were inf used with ACSF (black squares) or $1.0 \mu \mathrm{g}$ of U0126 (dark gray triangles) $24 \mathrm{hr}$ before conditioning and STM testing. D, Cannula tip placements from rats trained with multiple pairings and tested for fear memory at $1,3,6$, and $24 \mathrm{hr}$ after conditioning (see Fig. $5 C-G$ ). Rats were infused with ACSF (black squares), $0.1 \mu \mathrm{g}$ of U0126 (white triangles), or 1.0 $\mu \mathrm{g}$ of U0126 (dark gray triangles). Panels were adapted from Paxinos and Watson (1997).

experiment before and $40 \mathrm{~min}$ after LTP induction. It is evident in the figure that U0126-treated cells showed impaired LTP shortly after the pairing protocol and remained impaired throughout the testing session. An ANOVA (group $\times$ time) showed a significant effect for group $\left(F_{(1,7)}=7.06 ; p<0.05\right)$, a significant effect of time $\left(F_{(44,308)}=2.05 ; p<0.01\right)$, and a nonsignificant group $\times$ time interaction $\left(F_{(44,308)}=0.68\right)$. Newman-Keuls post hoc $t$ tests showed that there was a significant difference between vehicle and U0126-treated cells at every time point $(p<0.05)$. Furthermore, baseline synaptic transmission was not affected by U0126 (Fig. 7C). The ANOVA (across time) for synaptic transmission scores revealed no significant effects $\left(F_{(50,100)}=1.17\right)$. Thus, treatment with U0126 impairs both fear memory consolidation and synaptic plasticity in the LA.

\section{DISCUSSION}

Several recent studies have implicated the ERK/MAPK signaling pathway in fear memory consolidation. Ras-deficient mice have been shown to have impaired fear memory consolidation, as well as
LTP in the amygdala (Brambilla et al., 1997). Furthermore, recent behavioral studies have shown that either systemic (Atkins et al., 1998; Selcher et al., 1999) or intracerebroventricular (Schafe et al., 1999) administration of drugs that block ERK/MAPK activation impairs fear memory consolidation. In contrast to these previous studies that used more global manipulations, the present series of experiments evaluated the role of ERK/MAPK in fear memory consolidation specifically in the LA. Additionally, we asked whether ERK/MAPK activation is required for LTP in the LA. The findings indicated that ERK/MAPK was transiently activated in the amygdala, particularly the LA, after fear conditioning, and that this effect was specific to associative presentations of tone and shocks. Furthermore, pharmacological inhibition of ERK/MAPK activation in the LBA impaired memory consolidation of auditory fear conditioning after either single- or multiple-trial fear conditioning. Finally, bath application of U0126 to amygdala slices impaired LTP in the LA without affecting routine synaptic transmission. Collectively, the findings of the present study strongly favor the view that an ERK/MAPK-dependent process underlies memory consolidation and synaptic plasticity in the amygdala and build nicely on the findings of recent papers that have demonstrated the involvement of other intracellular processes in the amygdala in fear memory consolidation, including protein and RNA synthesis, and PKA (Bailey et al., 1999; Schafe and LeDoux, 2000).

The involvement of ERK/MAPK in both LTP and fear memory consolidation parallels that required for simpler forms of synaptic plasticity in invertebrates. In Aplysia cocultured sensory and motor neurons, inhibition of MAP kinase activity by anti-MAPK antibodies or the MEK inhibitor PD098059 selectively interferes with long-term facilitation (LTF) but has no effect on short-term facilitation (Martin et al., 1997). Furthermore, stimulation that leads to LTF has been shown to be accompanied by translocation of MAP kinase to the sensory neuron nucleus in which it is thought to engage activators of transcription (Martin et al., 1997). These findings are in parallel to those of the LTP literature in which treatment with the cAMP activator forskolin has been shown to lead to activation and nuclear translocation of ERK/MAPK in hippocampus (Martin et al., 1997). Furthermore, pharmacological inhibition of the ERK/MAPK signaling pathway in the hippocampus impairs LTP in area CA1 (English and Sweatt, 1996, 1997; Atkins et al., 1998; Coogan et al., 1999; Kanterewicz et al., 2000), and LTP-inducing stimulation of hippocampal cells leads to increases in CRE-mediated transcription, an effect that is blocked, along with LTP, by inhibitors of ERK/M APK activation (Impey et al., 1998b). Collectively, these findings are consistent with the view that synaptic plasticity in a wide range of species involves activation and nuclear translocation of ERK/MAPK where it may interact with nuclear transcription factors to promote the long-lasting protein synthesis-dependent changes thought to underlie memory formation.

Recently, it has become clear that the cAMP-response elementbinding protein (CREB) is a nuclear target of MAPKs (Frank and Greenberg, 1994; Impey et al., 1998b; Roberson et al., 1999). A number of studies have implicated CREB in a variety of forms of learning and memory in both invertebrates and vertebrates (Yin et al., 1994, 1995; Guzowski and McGaugh, 1997; Kogan et al., 1997; Lamprecht et al., 1997). Importantly, transgenic mice lacking the $\alpha$ and $\delta$ isoforms of CREB have been shown to have impaired LTM, but not STM, for auditory and contextual fear conditioning (Bourtchuladze et al., 1994). Together with the findings of the present studies, these observations suggest that fear memory consolidation in the LBA may involve activation of nuclear transcription factors such as CREB. In support of this hypothesis, CREmediated gene transcription has been shown recently to increase in the amygdala after contextual fear conditioning (Impey et al., 1998a), and overexpression of CREB in the LBA using viral vectors has been shown to facilitate LTM of fear-potentiated startle (Josselyn et al., unpublished observations). The extent to which the involvement of CREB in the LBA in memory consolidation of fear 
A.

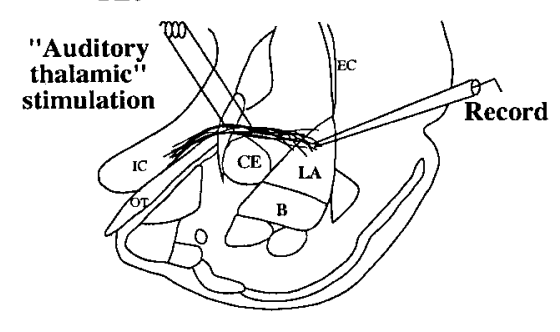

C.

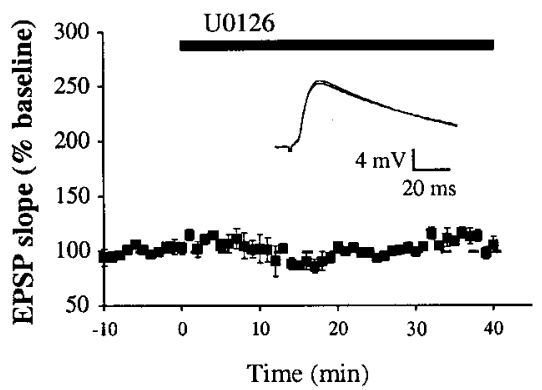

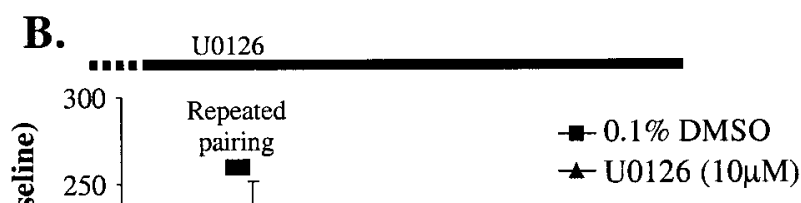

$\star \mathrm{U} 0126(10 \mu \mathrm{M})$

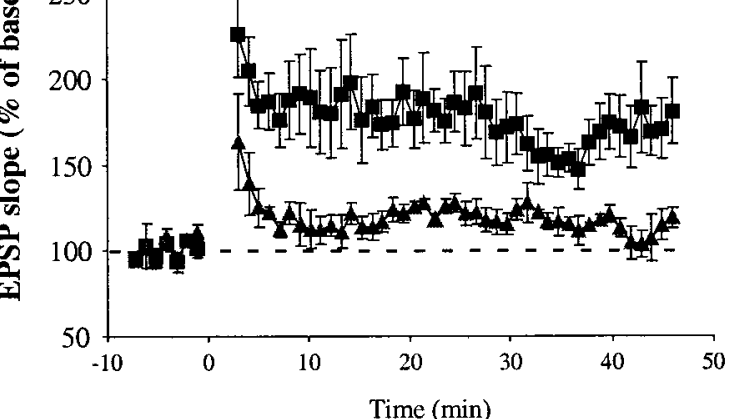

Time (min)

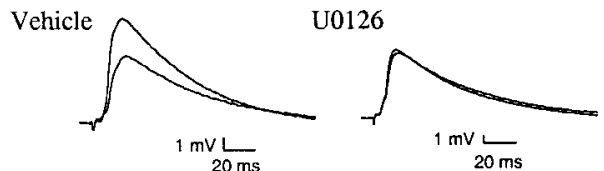

Figure 7. Impaired amygdala LTP by U0126. A, Schematic of the amygdala slice preparation, showing placement of stimulating and recording electrodes. Afferent fibers from the auditory thalamus enter the LA medially, coursing through the ventralmost part of the striatum just above the central nucleus. Recordings were made just below the site of termination of auditory thalamic fibers terminating in the LAd. IC, Internal capsule; $O T$, optic tract; $E C$, external capsule. $B$, Mean \pm SE percent EPSP slope (relative to baseline) in cells treated with $0.1 \%$ DMSO vehicle $(n=5$; black squares) or $10 \mu M$ U0126 $(n=4$; gray triangles) before and after LTP induction. U0126 was applied at the time indicated by solid bar, plus variable time before breaking into the cell indicated by dashed bar. Traces from an individual experiment before and 40 min after induction are shown in the inset. Traces are averages of five responses. $C$, Mean \pm SE percent EPSP slope (relative to baseline) in cells $(n=3)$ before and after treatment with U0126 (10 $\mu$ M; solid bar). Traces from an individual experiment before and $30 \mathrm{~min}$ after application of U0126 are shown in the inset. Traces are averages of five responses.

is dependent on activation by the ERK/MAPK signaling pathway remains to be determined.

Interestingly, we have shown recently that intra-LBA administration of inhibitors of PKA activity dose-dependently impairs memory consolidation of auditory fear conditioning (Schafe and LeDoux, 2000). Like the results obtained using U0126 in the present study, immediate post-training infusions of Rp-cAMPS impaired LTM of auditory fear conditioning but left STM intact. This pattern of results is consistent with a recent report showing impaired amygdala LTP after bath application of Rp-cAMPS (Huang and Kandel, 1998), and, along with the present findings, suggests that both PKA and MAPK are involved in synaptic plasticity and fear memory consolidation in the LBA. Consistent with this hypothesis, recent reports have shown that nuclear translocation of activated ERK/MAPK and $\mathrm{Ca}^{2+}$ stimulation of CREmediated gene transcription depends on PKA (Impey et al., 1998b). Furthermore, it has been shown recently that both PKA and PKC are upstream regulators of ERK/MAPK in area CA1 of the hippocampus and that PKA-mediated CREB phosphorylation depends on ERK/MAPK activation (Roberson et al., 1999). Collectively, these findings suggest a complex interaction between protein kinase signaling cascades in gene expression and synaptic plasticity. The extent to which PKA and ERK/MAPK interact in the LBA to promote gene transcription and fear memory is a question that awaits further study.

The impairment of fear memory consolidation as well as amygdala LTP by U0126 provides further evidence that an LTP-like process in the LA may underlie fear memory consolidation. Previous studies have demonstrated the involvement of ERK/MAPK in multiple forms of hippocampal LTP (English and Sweatt, 1997; Atkins et al., 1998; Impey et al., 1998b; Coogan et al., 1999; Kanterewicz et al., 2000). In the present experiments, we show that bath application of U0126 impairs associative "thalamic" LTP in the LA induced by pairing trains of presynaptic stimulation with postsynaptic depolarization. This induction protocol, which is known to produce backpropagating action potentials and to open voltage-gated calcium channels (VGCCs) (Stuart et al., 1997), has been shown to produce an NMDA-independent form of LTP that is blocked by the L-type VGCC blocker nifedipine (Weisskopf et al., 1999). Collectively, these findings suggest that $\mathrm{Ca}^{2+}$ influx via VGCCs and resultant ERK/MAPK activation may be an important series of initial events whereby long-term fear memories are established in the LA (Fig. 8). We are currently addressing this important question in our laboratory.

In the present study, STM of auditory fear was intact to $3 \mathrm{hr}$ after inf usion of U0126 and fear conditioning but was impaired at 6 and $24 \mathrm{hr}$. This time course of memory decay is consistent with a recent report from our laboratory showing intact STM at $4 \mathrm{hr}$ after conditioning and treatment with inhibitors of protein synthesis or PKA activity (Schafe and LeDoux, 2000). It is also consistent with reports that have shown that fear memory is insensitive to disruption by inhibitors of protein synthesis and PKA at $6 \mathrm{hr}$ after training (Bourtchuladze et al., 1998; Schafe and LeDoux, 2000). Collectively, these findings suggest a fairly long time course of memory decay after disruption of intracellular processes necessary for LTM. However, it is obvious that amygdala LTP under the influence of U0126 was impaired almost immediately after induction. This pattern of results is quite common in the literature, particularly in those studies using slice physiology in which STM is almost invariably observed to last longer than LTP after the same manipulation. For example, Brambilla et al. (1997) observed intact contextual and auditory fear STM in Ras-deficient mice at $30 \mathrm{~min}$ after training (longer periods were not evaluated), but LTP in amygdala slices from Ras-deficient mice was impaired almost immediately after induction and decayed to baseline levels by $30 \mathrm{~min}$. Similarly, both $\alpha / \delta$ CREB knock-outs and mice overexpressing $\mathrm{R}(\mathrm{AB})$, an inhibitory form of PKA, were shown to have intact contextual fear memory from 30 to $60 \mathrm{~min}$, respectively, after fear conditioning, whereas LTP, measured in hippocampus, was impaired almost immediately after induction (Bourtchuladze et al., 1994; Abel et al., 1997). Thus, there appears to be a discrepancy between the time course of memory decay and LTP decay, which clearly suggests that LTP induction in the laboratory is unlikely to represent an accurate model of the establishment of a short-term 


\section{LA Principal Neuron}

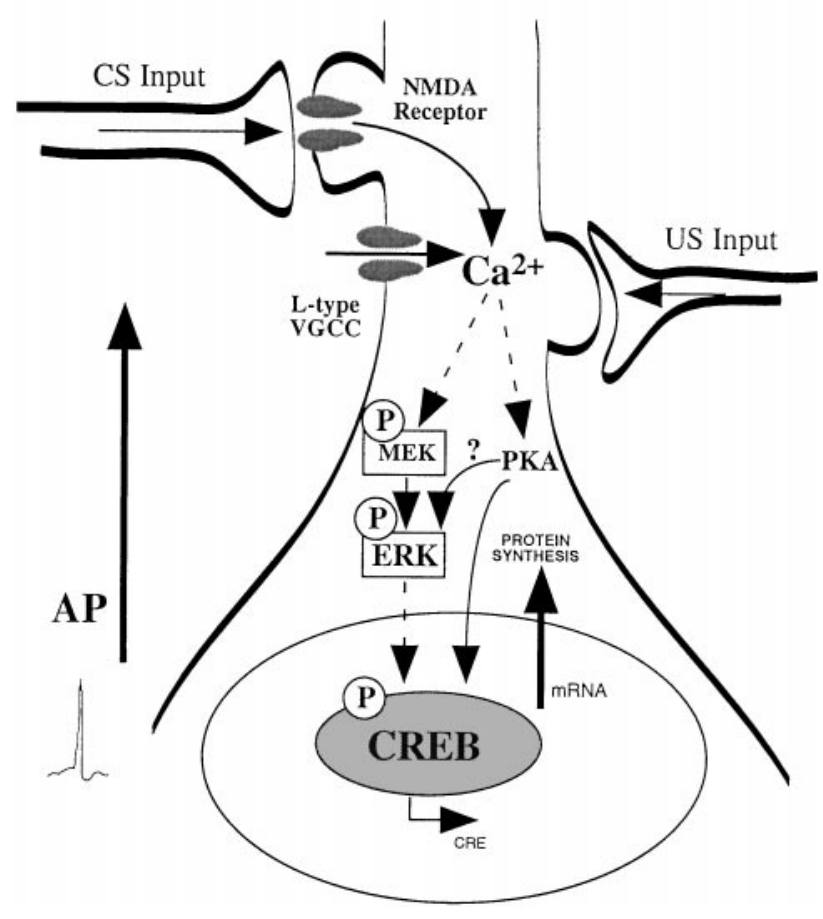

Figure 8. Schematic of the cellular events that may underlie formation of long-term fear memories in the amygdala. Pairing of CS and US inputs in LA principal cells leads to calcium influx through either NMDA receptors or L-type VGCCs. L-type channels are opened on dendritic shafts and spines, possibly by backpropagating action potentials $(A P)$ during training. The increase in intracellular $\mathrm{Ca}^{2+}$ leads to the activation of protein kinases, such as PKA and ERK/MAPK. Once activated, these kinases can translocate to the nucleus where they activate transcription factors such as CREB. The activation of CREB by PKA and ERK/MAPK promotes CRE-mediated gene transcription and the synthesis of new proteins. PKA, ERK/MAPK, CREB, RNA, and protein synthesis in the amygdala have all been shown to be necessary for the establishment of long-term fear memories.

memory trace per se. However, it may be possible that STM and LTM are independent cellular processes that are characterized by distinct molecular mechanisms and that a process akin to LTP induction engages the long-term process exclusive of the short-term process in the behaving animal. If true, this may account for why so many manipulations that disrupt LTP also impair LTM but not necessarily STM. Additional experiments, particularly in awake rats in which both electrophysiology and behavior can be evaluated simultaneously, will be necessary to evaluate this question.

The results of the present study clearly suggest that an ERK/ MAPK-dependent process underlies synaptic plasticity and fear memory consolidation in the LBA. These findings expand nicely on those of previous studies showing the involvement of ERK/ MAPK in other types of learning and memory in tissue-specific areas, such as insular cortex or hippocampus (Berman et al., 1998; Blum et al., 1999), and make an important first step toward understanding the cellular and molecular processes underlying emotional memory formation in the amygdala.

\section{REFERENCES}

Abel T, Nguyen PV, Barad M, Deuel TAS, Kandel ER, Bourchuladze R (1997) Genetic demonstration of a role for PKA in the late phase of LTP and in hippocampus-based long-term memory. Cell 88:615-626.

Atkins CM, Selcher JC, Petraitis JJ, Trzaskos JM, Sweatt JD (1998) The MAPK cascade is required for mammalian associative learning. Nat Neurosci 1:602-610.

Bailey DJ, Kim JJ, Sun W, Thompson RF, Helmstetter FJ (1999) Acqui- sition of fear conditioning in rats requires the synthesis of mRNA in the amygdala. Behav Neurosci 113:276-282.

Berman DE, Hazvi S, Rosenblum K, Seger R, Dudai Y (1998) Specific and differential activation of mitogen-activated protein kinase cascades by unfamiliar taste in the insular cortex of the behaving rat. J Neurosci 18:10037-10044.

Blum S, Moore AN, Adams F, Dash PK (1999) A mitogen-activated protein kinase cascade in the CA1/CA2 subfield of the dorsal hippocampus is essential for long-term spatial memory. J Neurosci 19:3535-3544.

Bourtchuladze R, Frenguelli B, Blendy J, Cioff D, Schutz G, Silva AJ (1994) Deficient long-term memory in mice with a targeted mutation of the cAMP-responsive element-binding protein. Cell 79:59-68.

Bourtchuladze R, Abel T, Berman N, Gordon R, Lapidus K, Kandel ER (1998) Different training procedures recruit either one or two critical periods for contextual memory consolidation, each of which requires protein synthesis and PKA. Learn Mem 5:365-374.

Brambilla R, Gnesutta N, Minichiello L, White G, Roylance AJ, Herron CE, Ramsey M, Wolfer VC, Cestari V, Rossi-Arnaud C, Grant SE, Chapman PF, Lipp H-P, Sturani E, Klein R (1997) A role for the Ras signaling pathway in synaptic transmission and long-term memory. Nature 390:281-286.

Chapman PF, Kairiss EW, Keenan CL, Brown TH (1990) Long-term synaptic potentiation in the amygdala. Synapse 6:271-278.

Clugnet M, LeDoux JE (1990) Synaptic plasticity in fear conditioning circuits: induction of LTP in the lateral nucleus of the amygdala by stimulation of the medial geniculate body. J Neurosci 10:2818-2824.

Coogan AN, O'Leary DM, O'Conner JJ (1999) p42/44 MAP kinase inhibitor PD098059 attenuates multiple forms of synaptic plasticity in rat dentate gyrus in vitro. J Neurophysiol 81:103-110.

English JD, Sweatt JD (1996) Activation of p42 mitogen-activated protein kinase in hippocampal long-term potentiation. J Biol Chem 271:2432924332.

English JD, Sweatt JD (1997) A requirement for the mitogen-activated protein kinase cascade in hippocampal long-term potentiation. J Biol Chem 272:19103-19106.

Favata MF, Horiuchi KY, Manos EJ, Daulerio AJ, Stradley DA, Feeser WS, Van Dyk DE, Pitts WJ, Earl RA, Hobbs F, Copeland RA, Magolda RL, Scherle PA, Trzaskos JM (1998) Identification of a novel inhibitor of mitogen-activated protein kinase kinase. J Biol Chem 273:18623-18632.

Fendt M, Fanselow MS (1999) The neuroanatomical and neurochemical basis of conditioned fear. Neurosci Biobehav Rev 23:743-760.

Frank DA, Greenberg ME (1994) CREB: a mediator of long-term memory from mollusks to mammals. Cell 79:5-8.

Guzowski JF, McGaugh JL (1997) Antisense oligodeoxynucleotidemediated disruption of hippocampal cAMP response element binding protein levels impairs consolidation of memory for water maze training. Proc Natl Acad Sci USA 94:2693-2698.

Huang YY, Kandel ER (1998) Postsynaptic induction and PKA-dependent expression of LTP in the lateral amygdala. Neuron 21:169-178.

Impey S, Smith DM, Obrietan K, Donahue R, Wade C, Storm DR (1998a) Stimulation of cAMP response element (CRE)-mediated transcription during contextual learning. Nat Neurosci 1:595-601.

Impey S, Obrietan K, Wong S, Poser S, Yano S, Wayman G, Deloulme JC, Chan G, Storm DR (1998b) Cross talk between ERK and PKA is required for $\mathrm{Ca}^{2+}$ stimulation of CREB-dependent transcription and ERK nuclear translocation. Neuron 21:869-883.

Impey S, Obrietan K, Storm DR (1999) Making new connections: role of ERK/MAP kinase signaling in neuronal plasticity. Neuron 23:11-14.

Kanterewicz BI, Urban NN, McMahon DB, Norman ED, Giffen LJ, Favata MF, Scherle PA, Trzskos JM, Barrionuevo G, Klann E (2000) The extracellular signal-regulated kinase cascade is required for NMDA receptor-independent LTP in area CA1 but not area CA3 of the hippocampus. J Neurosci 20:3057-3066.

Kogan JH, Frankland PW, Blendy JA, Coblentz J, Marowitz Z, Schutz G, Silva AJ (1997) Spaced training induces normal long-term memory in CREB mutant mice. Curr Biol 7:1-11.

Kornhauser JM, Greenberg ME (1997) A kinase to remember: dual roles for MAP kinase in long-term memory. Neuron 18:839-842.

Lamprecht R, Hazvi S, Dudai Y (1997) cAMP response element-binding protein in the amygdala is required for long- but not short-term conditioned taste aversion memory. J Neurosci 17:8443-8450.

LeDoux JE (2000) Emotion circuits in the brain. Annu Rev Neurosci 23:155-184.

LeDoux JE, Farb C, Ruggiero DA (1990) Topographic organization of neurons in acoustic thalamus that project to the amygdala. $\mathrm{J}$ Neurosci 10:1043-1054.

Malkani S, Rosen JB (2000) Specific induction of early growth response gene 1 in the lateral nucleus of the amygdala following contextual fear conditioning in rats. Neuroscience 97:693-702.

Maren S (1999) Long-term potentiation in the amygdala: a mechanism for emotional learning and memory. Trends Neurosci 22:561-567.

Markram H, Lübke J, Frotscher M, Sakmann B (1997) Regulation of synaptic efficacy by coincidence of postsynaptic APs and EPSPs. Science 275:213-215.

Martin KC, Michael D, Rose JC, Barad M, Casadio A, Zhu H, Kandel ER (1997) MAP kinase translocates into the nucleus of the presynaptic cell and is required for long-term facilitation in Aplysia. Neuron 18:899-912. 
McKernan MG, Shinnick-Gallagher P (1997) Fear conditioning induces a lasting potentiation of synaptic currents in vitro. Nature 390:607-611.

Oruban PC, Chapman PF, Brambilla R (1999) Is the Ras-MAPK signalling pathway necessary for long-term memory formation? Trends Neurosci $22: 38-44$

Paxinos G, Watson C (1997) The rat brain in stereotaxic coordinates: computer graphics files, Ed 3. San Diego: Academic.

Roberson ED, English JD, Adams JP, Selcher JC, Kondratick C, Sweatt JD (1999) The mitogen-activated protein kinase cascade couples PKA and $\mathrm{PKC}$ to $\mathrm{CAMP}$ response element binding protein phosphorylation in area CA1 of hippocampus. J Neurosci 19:4337-4348.

Rogan MT, LeDoux JE (1995) LTP is accompanied by commensurate enhancement of auditory-evoked responses in a fear conditioning circuit. Neuron 15:127-136.

Rogan MT, Staubli U, LeDoux JE (1997) Fear conditioning induces associative long-term potentiation in the amygdala. Nature 390:604-607.

Rosen JB, Fanselow MS, Young SL, Sitcoske M, Maren S (1998) Immediate-early gene expression in the amygdala following footshock stress and contextual fear conditioning. Brain Res 796:132-142.

Rosen LB, Ginty DD, Weber MJ, Greenberg ME (1994) Membrane depolarization and calcium influx stimulate MEK and MAP kinase via activation of ras. Neuron 12:1207-1221.

Schafe GE, LeDoux JE (2000) Memory consolidation of auditory Pavlovian fear conditioning requires protein synthesis and PKA in the amygdala. J Neurosci RC96:1-5.
Schafe GE, Nadel NV, Sullivan GM, Harris A, LeDoux JE (1999) Memory consolidation for contextual and auditory fear memory is dependent on protein synthesis, PKA, and MAP kinase. Learn Mem 6:97-110.

Selcher JC, Atkins CM, Trzaskos JM, Paylor R, Sweatt JD (1999) A necessity for MAP kinase activation in mammalian spatial learning. Learn Mem 6:478-490.

Stuart G, Spruston N, Sakmann B, Hauser M (1997) Action potential initiation and backpropagation in neurons of the mammalian CNS. Trends Neurosci 20:125-131.

Swank MW (2000a) Phosphorylation of MAP kinase and CREB in mouse cortex and amygdala during taste aversion learning. NeuroReport 11:1625-1630.

Swank MW (2000b) Pharmacological antagonism of tyrosine kinases and MAP kinase in brainstem blocks taste aversion learning in mice. Physiol Behav 69:499-503.

Weisskopf MG, Bauer EP, LeDoux JE (1999) L-type voltage-gated calcium channels mediate NMDA-independent associative long-term potentiation at thalamic input synapses to the amygdala. J Neurosci 19:10512-10519.

Yin JCP, Wallach JS, Del Vecchio M, Wilder EL, Zhuo H, Quinn WG, Tully T (1994) Induction of a dominant negative CREB transgene specifically blocks long-term memory in Drosophila. Cell 79:49-58.

Yin JCP, Del Vecchio M, Zhuo H, Tully T (1995) CREB as a memory modulator: induced expression of a dCREB2 activator isoform enhances long-term memory in Drosophila. Cell 81:107-115. 